\title{
Knowledge, Practice and Barriers of Health Care Wastes Segregation Among Health Care Providers in University of Gondar Comprehensive Specialized Hospital, Northwest Ethiopia, 2017
}

\author{
AbebaFenta Tewabe ${ }^{1}$, Tiruneh ${ }^{2}$, YaredAsmare Abej ${ }^{3}$, Tarkie Abebe Walle*4 \\ ${ }^{1}$ Clinical nurse at university of Gondar specialized hospital Gondar, Bachelor of Science Degree in Nursing, Ethiopia \\ ${ }^{2}$ Lecturer at the school of nursing, College of Medicine and Health Sciences at University of Gondar, Ethiopia \\ ${ }^{3}$ Lecturer at the school of medicine, College of Medicine and Health Sciences at University of Gondar, Bachelor of Science Degree in physiotherapy, and MSc in \\ Human anatomy, Ethiopia \\ ${ }^{4}$ Lecturer and a nurse practitioner in the school of nursing, College of Medicine and Health Sciences at University of Gondar, Bachelor of Science Degree in \\ Nursing, Ethiopia
}

Received: 非: September 26, 2018; Published: 制: October 09, 2018

*Corresponding author: Tarkie Abebe, Clinical nurse at university of Gondar specialized hospital Gondar Ethiopia she has a Bachelor of Science Degree in Nursing, MSc in Surgical Nursing Specialization, Ethiopia

Abstract

Background: Healthcare wastes can be potentially risky to health care providers, patients', the community and the environment particularly when it is inappropriately placed at the time of generation. Data on the knowledge and practice of healthcare professionals on health care waste segregation is scarce in our setting. Therefore, the objective of the study was to assess knowledge, practice and associated factors of health care waste segregation among health care providers at University of Gondar Comprehensive Specialized Hospital, Northwest Ethiopia, 2017.

Methods: Institution based cross sectional study was conducted from April 10 to May 10, 2017. Pretested self-administered questionnaire and observational checklist were used. The data was coded, cleaned and entered into Epi Info version 7statistical software and analyzed using SPSS version 20 .

Result: This study revealed that health care providers who had adequate knowledge and appropriate practice about health care waste segregation were $39 \%$ and $42.6 \%$ respectively. In the multivariable analysis training (AOR $1.81 \mathrm{CI} 95 \%$ 1.15, 2.88), and reward (AOR $1.80 \mathrm{CI} 95 \% 1.10,2.89$ ) were significantly associated with the knowledge. And training (AOR $1.71 \mathrm{CI} 95 \% 1.08,2.71$ ), personal needs to use personal protective equipment for health care waste handling (AOR 3.15 CI 95\% 1.97, 4.45), were significantly associated with the practice of health care waste segregation.

Conclusion and Recommendation: Health care providers' knowledge and practice towards health care waste segregation in University of Gondar Comprehensive Specialized hospital was inadequate. Training and reward were significantly associated with knowledge. And training and personal needs to use personal protective equipment for handling health care waste segregation were associated with practice of health care providers on health care waste segregation. Provide regular training and rewarding to the health care providers is important.

Keywords: Health Care Provider; Health Care Waste Segregation; Knowledge; Practice

\section{Introduction}

Healthcare Wastes (HCW) are any waste which is generated during the diagnosis, treatment or immunization of human beings from healthcare organizations such as hospitals [1]. Waste segregation is the essence of waste disposal at the source of HCW generation during health care provision [2]. HCW have been a source of infectious diseases to the healthcare staff, clients, and for the general community particularly when wastes segregated on the wrong way. According to 2015 WHO report from the total amount of HCW generated though health-care activities nearly $15 \%$ of it holds hazardous waste [3]. The contribution of inappropriate practice and inadequate knowledge to the placing of HCW by health care providers were results to serious consequences of health problem and a significant impact on the health care delivery, environment and community as a whole [4]. Different study showed that inappropriate segregation of waste poses serious health risks for waste handlers, waste collectors, patients and health care provider's [5-7]. There is also strong evidence that HIV and hepatitis viruses B and $\mathrm{C}$ transmitted via health care waste [1]. 
Among these health risks and risk of infection transmission on HIV/AIDS $0.3 \%$, Viral Hepatitis B (HBV) 1.8\% and Hepatitis C (HCV) 30\% respectively [3]. In spite of the fact that health care wastes have a serious consequence, it's has not received sufficient attention because of unavailability of responsible person, HCWMC, guide line and, insufficiently color coded bin, and also inconsistence training health care workers are not knowledgeable and practice as standards [8-13]. As a preliminary observation and interview result from the key respondent of health providers the researcher observed the University of Gondar Comprehensive Specialized Hospital (UGCSH) wastages are not properly segregated due to lack of PPE, color-coded bin, lack of training about infection prevention and health care waste management, unavailability of guidelines, absence of responsible person and weak supervision, absence of staff motivation, low monthly income (salary), professional category, working section (department). These problems lead to the expose to sharp injury and infection for HCPs, patients and environment especially for HIV, hepatitis B, and hepatitis C, unfavorable working climate $[12,14]$.

Despite of these problems, the knowledge and the practice limitation of health care providers towards health care waste segregation plays a significant role [15]. Therefore, the aim of this study was to assess the knowledge, practices and factors associated with health waste segregation among health care providers at University of Gondar Comprehensive Specialized Hospital, Northwest Ethiopia.

\section{Methods and Materials}

An institution based cross-sectional study was conducted from April 10 to May 10, 2017. The study was conducted at University of Gondar Comprehensive Specialized Hospital North Gondar Administrative Zone, Amhara National Regional State. It is located at about $748 \mathrm{~km}$ and $180 \mathrm{~km}$ far from Addis Ababa and Bahirdar respectively. University of Gondar is one of the Universities in Ethiopia established in 1954 as a Public Health College and Training Centre. All health care providers working at University of Gondar Comprehensive Specialized Hospital were the source population. Health professionals who had less than six months of working experience were excluded. The sample size was determined by using single population proportion formula to obtain the sample size needed to estimate the knowledge and practice of health care wastes segregation among health care providers in university of Gondar comprehensive specialized hospital.

$$
n=\frac{(z \alpha / 2) 2 p(1-p)}{d^{2}}
$$

So the total sample size was 420 by adding $10 \%$ non-respondent rate. According to their professional category participants were assigned proportionally. Simple random sampling technique was used. Data were collected by using structured and pre-tested selfadministered questionnaire and observational checklist that was developed after reviewing related studies [16-26]. It was modified to fit the study population. Observational checklist was used to assess the practice in terms of segregation. Pre-test was conducted on five percent of the questionnaire to check compatibility of the tool and training was given for data collectors and supervisors before actual data collection. Data were checked for completeness, coded and entered to Epi-info version 7 statistical software and was exported to SPSS (Statistical Package for Social Science) windows version 20 for analysis.

Frequencies and cross tabulations were used to summarize descriptive statistics of the data. Bivariate logistic analysis was used primarily to check variables which have associations with the dependent variable. Model fitness was checked by using Hosmer and lemeshow goodness of fit which was $>0.05$. Significant and nonsignificant variables in the bivariate analysis were then entered into multiple logistic regression for controlling the possible effect of confounders and finally the variables with significant association at P-value $<0.05$ were identified on the basis of Odds Ratio with $95 \%$ confidence interval.

\section{Operational Definition}

a. Health Care Provider: Healthcare provider was included physicians, nurses, midwifes, laboratory technicians, anaesthetist and physiotherapist.

b. Adequate Knowledge: If the study participant who scored above or equal to the mean score of 8.3 from the knowledge questions was taken as adequate knowledge.

c. Inadequate Knowledge: If the participant scored below the mean score, then taken as inadequate Knowledge.

d. Appropriate Practice: If the participant achieved above or equal to the mean score of 4.9 from the practice questions, then taken as appropriate practice.

e. Inappropriate Practice: if the participant achieved below the mean score, then taken as inappropriate practice.

\section{Result}

\section{Socio Demographic Characteristics}

A total of 420 participants were participated in the study with $100 \%$ response rate. $52.1 \%$ were males. The mean age of the respondents was $28.6(\mathrm{SD}+5.3)$ years. Two thirds of them $(63.1 \%)$ were single and two thirds of them $(63 \%)$ were nurses. $97.4 \%$ were degree holders. One third of them (35.2\%) have monthly income of less than 4446 Ethiopia birr. Two thirds of them (74.5\%) had below five year experience (Table 1).

Table 1: Socio demographic characteristics of the respondents for the study of knowledge, practice and associated factors of health care waste segregation among health care providers at University of Gondar Comprehensive Specialized Hospital, Northwest Ethiopia, 2017 ( $\mathrm{n}=420)$.

\begin{tabular}{|c|c|c|c|}
\hline \multirow{2}{*}{ Variables } & \multirow{2}{*}{ Variable category } & \multicolumn{2}{|c|}{ Frequency } \\
\cline { 2 - 4 } & Male & $\mathbf{n = 4 2 0}$ & $\mathbf{2 1 9}$ \\
\hline \multirow{2}{*}{ Sex } & Female & 201 & 52.1 \\
\cline { 2 - 4 } & $20-25$ years & 110 & 47.9 \\
\hline \multirow{2}{*}{ Age } & $25-30$ years & 216 & 51.4 \\
\cline { 2 - 4 } & 30-35 years & 59 & 14.0 \\
\cline { 2 - 4 } & & &
\end{tabular}




\begin{tabular}{|c|c|c|c|}
\hline \multirow{2}{*}{ Marital status } & $>35$ years & 35 & 9.4 \\
\hline \multirow{3}{*}{ Level of education } & Single & 265 & 63.1 \\
\hline \multirow{4}{*}{ Profession } & Married & 155 & 36.9 \\
\cline { 2 - 4 } & Diploma & 11 & 3 \\
\cline { 2 - 4 } & Degree and above & 409 & 97 \\
\cline { 2 - 4 } & Nurse & 266 & 63 \\
\hline \multirow{3}{*}{ Monthly income } & others ${ }^{\text {a }}$ & 46 & 11 \\
\cline { 2 - 4 } & $<4446$ & 148 & 35.2 \\
\cline { 2 - 4 } & $4446-5546$ & 62 & 14.8 \\
\cline { 2 - 4 } & $5546-9217$ & 105 & 25 \\
\hline \multirow{3}{*}{ Working Experience } & $>9217$ & 105 & 25 \\
\cline { 2 - 4 } in years & $<5$ years & 313 & 74.4 \\
\cline { 2 - 4 } & $10-10$ years & 81 & 19.2 \\
\cline { 2 - 4 } & $>15$ years & 16 & 4 \\
\hline
\end{tabular}

\begin{tabular}{|c|c|c|c|}
\hline \multirow{2}{*}{$\begin{array}{c}\text { Length of stay } \\
\text { on working }\end{array}$} & 8 hours & 142 & 33.8 \\
\cline { 2 - 4 } & $>8$ hours & 278 & 66.2 \\
\hline \multirow{2}{*}{ working section } & OPD & 93 & 22 \\
\cline { 2 - 4 } & Ward & 327 & 78 \\
\hline
\end{tabular}

Key: a $=$ Represents other professionals included laboratory technologist, physiotherapy, anesthesiologist, OPD = Outpatient department.

\section{Knowledge}

In this study 164 (39\%), N=420 of the study participants had adequate knowledge regardless of health care waste segregation. Among this $97(57.3 \%$ ) and $85(51.8 \%)$ of the respondent were males and in the age group of 20-25 years respectively. $110(67 \%)$ of the respondent were unmarried. And 98(59.8\%) were nurse. $163(99.4 \%)$ of the participants were degree and above. In the multivariate analysis variables like, training [AOR: 1.81, 95\%CI: $1.15,2.86]$ and rewarding [AOR: 1.8, 95\% CI: 1.1, 2.89] were associated with the outcome variable (Table 2).

Table 2: Associated variables with knowledge on health care waste segregation among health care providers at University of Gondar Comprehensive Specialized Hospital, Northwest Ethiopia, 2017(n=420).

\begin{tabular}{|c|c|c|c|c|c|}
\hline \multirow{2}{*}{ Variable } & \multirow{2}{*}{ Category } & \multicolumn{2}{|c|}{ Knowledge } & \multirow{2}{*}{$\operatorname{COR}(95 \% \mathrm{CI})$} & \multirow{2}{*}{ AOR(95\%CI) } \\
\hline & & Adequate knowledge $\mathrm{N}$ & Inadequate knowledge $\mathrm{N}$ & & \\
\hline \multirow{2}{*}{ Sex } & Male & 94 & 125 & $1.41(0.95,2.08)$ & $1.57(0.99,2.45)$ \\
\hline & Female & 70 & 131 & 1 & 1 \\
\hline \multirow{4}{*}{ Age } & 20-25 year & 45 & 65 & 1 & 1 \\
\hline & $25-30$ year & 85 & 131 & $0.93(0.59,1.49)$ & $1.05(0.61,1.77)$ \\
\hline & 30-35 year & 25 & 34 & $1.06(0.56,2.02)$ & $1.36(0.63,2.95)$ \\
\hline & $>35$ year & 9 & 26 & $0.50(0.21,1.17)$ & $0.69(0.21,2.24)$ \\
\hline \multirow{2}{*}{ Marital status } & Single & 110 & 155 & 1 & 1 \\
\hline & Married & 54 & 101 & $0.75(0.50,1.14)$ & $0.83(0.51,1.35)$ \\
\hline \multirow{3}{*}{ Profession } & Medical doctor & 51 & 57 & 1 & 1 \\
\hline & Nurse & 98 & 168 & $0.52(0.33,0.82)$ & $1.06(0.21,4.44)$ \\
\hline & Others & 9 & 37 & $0.22(0.09,0.49)$ & $0.59(0.005,1.66)$ \\
\hline \multirow{2}{*}{$\begin{array}{c}\text { Level of } \\
\text { qualification }\end{array}$} & Diploma & 1 & 10 & 1 & 1 \\
\hline & Degree and above & 163 & 246 & $6.62(0.84,52.25)$ & $5.58(0.65,48.79)$ \\
\hline \multirow{2}{*}{ Work section } & OPD & 22 & 71 & 1 & 1 \\
\hline & Ward & 142 & 185 & $2.48(1.46,4.19)$ & $1.80(0.93,3.50)$ \\
\hline \multirow{4}{*}{$\begin{array}{c}\text { Working } \\
\text { experience }\end{array}$} & $<5$ years & 129 & 184 & 1 & 1 \\
\hline & 5-10 years & 28 & 53 & $0.58(0.19,2.44)$ & $1.37(0.65,2.88)$ \\
\hline & $10-15$ years & 3 & 13 & $0.32(0.14,1.98)$ & $0.67(0.14,3.17)$ \\
\hline & $>15$ years & 4 & 6 & $0.95(0.41,5.09)$ & $4.37(0.77,24.28)$ \\
\hline \multirow{2}{*}{$\begin{array}{c}\text { Stay on } \\
\text { working }\end{array}$} & 8 hours & 53 & 89 & $0.89(0.59,1.36)$ & $1.07(0.66,1.75)$ \\
\hline & $>8$ hours & 111 & 164 & 1 & 1 \\
\hline \multirow{4}{*}{$\begin{array}{l}\text { Monthly } \\
\text { income }\end{array}$} & $<4446$ & 51 & 97 & 1 & 1 \\
\hline & $4446-5546$ & 31 & 31 & $0.64(0.28,0.77)$ & $1.36(0.69,2.79)$ \\
\hline & $5546-9217$ & 56 & 49 & $0.87(0.47,1.64)$ & $0.47(0.21,1.07)$ \\
\hline & $>9217$ & 26 & 79 & $0.29(0.16,0.52)$ & $1.64(0.32,8.48)$ \\
\hline \multirow{2}{*}{ Rewarding } & Yes & 63 & 70 & $1.66(1.09,2.51)$ & $1.80(1.10,2.89)^{*}$ \\
\hline & No & 101 & 186 & 1 & 1 \\
\hline
\end{tabular}

Cite this article: AbebaFenta Tewabe, Bewket Tadesse T,YaredAsmare A, TarkieAbebe W. Knowledge, Practice and Barriers of Health Care Wastes Segregation Among Health Care Providers in University of Gondar Comprehensive Specialized Hospital, Northwest Ethiopia, 2017. 


\begin{tabular}{|c|c|c|c|c|c|}
\hline \multirow{2}{*}{ Training } & Yes & 80 & 97 & $1.56(1.05,2.32)$ & $1.81(1.15,2.86)^{*}$ \\
\cline { 2 - 6 } & No & 84 & 159 & 1 & 1 \\
\hline $\begin{array}{c}\text { Availability of } \\
\text { sufficient }\end{array}$ & Yes & 63 & 122 & $1.46(0.98,2.17)$ & $1.31(0.78,2.18)$ \\
\hline $\begin{array}{c}\text { Color coded } \\
\text { bin }\end{array}$ & No & 101 & 134 & 1 & 1 \\
\hline $\begin{array}{c}\text { Availability of } \\
\text { PPE }\end{array}$ & Yes & 80 & 107 & $1.33(0.89,1.97)$ & $1.34(0.81,2.24)$ \\
\cline { 2 - 6 } & No & 84 & 149 & 1 & 1 \\
\hline
\end{tabular}

Key * = Represents variables significantly associated at P-value is $\leq 0.05, \mathrm{AOR}=$ Adjusted Odds Ratio, COD $=\mathrm{Crude}$ Odds Ratio, $\mathrm{PPE}$ $=$ Personal Protective Equipment, $\mathrm{OPD}=$ Outpatient Diagnosis .

\section{Practice Health}

Among the study participants $179(42.6 \%), \quad \mathrm{N}=420$ had appropriate practice of health care waste segregation. Of this $90(50.3 \%)$ were females and in the age group of 20-30 years. And $109(60.9 \%)$ were single. Of the participants $107(59.8 \%)$ were nurse and 175(97.8\%) were degree and above respectively. Most of the respondents work experience $120(70.4 \%)$ were five years and below. And their length of stay on work without rest 111(62\%) were eight hours and above. 104(58\%) were had adequate knowledge. In multivariable analysis training (AOR 1.71 CI 95\% $1.08,2.71$ ), personal needs to use personal protective equipment for health care waste handling (AOR 3.15 CI 95\% 1.97, 4.45), were significantly associated with the practice of health care waste segregation (Table 3).

Table 3: Associated variables with practice on health care waste segregation among health care providers at University of Gondar Comprehensive Specialized Hospital, Northwest Ethiopia, 2017(n=420).

\begin{tabular}{|c|c|c|c|c|c|}
\hline \multirow[b]{2}{*}{ Variable } & \multirow[b]{2}{*}{ Category } & \multicolumn{2}{|c|}{ Practice } & \multirow[b]{2}{*}{$\operatorname{COR}(95 \% \mathrm{CI})$} & \multirow[b]{2}{*}{ AOR(95\%CI) } \\
\hline & & Appropriate practice $\mathrm{N}$ & $\begin{array}{c}\text { Inappropriate practice } \\
\mathrm{N}\end{array}$ & & \\
\hline \multirow{2}{*}{ Sex } & Male & 89 & 130 & 1 & 1 \\
\hline & Female & 90 & 111 & $1.18(0.80,1.74)$ & $1.28(0.81,2.03)$ \\
\hline \multirow{4}{*}{ Age } & 20-25 year & 53 & 57 & 1 & 1 \\
\hline & 25-30 year & 89 & 127 & $0.75(0.47,1.19)$ & $0.69(0.41,1.17)$ \\
\hline & 30-35 year & 21 & 38 & $0.78(0.31,1.14)$ & $0.78(0.36,1.67)$ \\
\hline & $>35$ year & 16 & 19 & $0.91(0.42,1.94)$ & $1.18(0.41,3.38)$ \\
\hline \multirow{2}{*}{ Marital status } & Single & 109 & 156 & 1 & 1 \\
\hline & Married & 70 & 85 & $1.18(0.73,1.63)$ & $1.24(0.77,2.00)$ \\
\hline \multirow{3}{*}{ Profession } & Medical doctor & 55 & 53 & 1 & 1 \\
\hline & Nurse & 107 & 159 & $0.56(0.41,1.01)$ & $0.08(0.01,1.02)$ \\
\hline & Others & 25 & 21 & $0.56(0.28,1.15)$ & $0.80(0.23,2.71)$ \\
\hline \multirow{2}{*}{ Level of qualification } & Diploma & 5 & 6 & 1 & 1 \\
\hline & Degree and above & 175 & 234 & $1.31(0.37,4.54)$ & $1.84(0.47,7.29)$ \\
\hline \multirow{2}{*}{ Work section } & OPD & 29 & 64 & $0.53(0.33,0.87)$ & $0.59(0.31,1.13)$ \\
\hline & Ward & 201 & 126 & 1 & 1 \\
\hline \multirow{4}{*}{ Monthly income } & $<4446$ & 66 & 82 & 1 & 1 \\
\hline & $4446-5546$ & 20 & 42 & $0.59(0.31,1.10)$ & $0.57(0.27,1.18)$ \\
\hline & 5546-9217 & 38 & 67 & $0.56(0.34,0.93)$ & $0.72(0.34,1.51)$ \\
\hline & $>9217$ & 50 & 55 & $1.05(0.63,1.75)$ & $2.84(0.44,3.27)$ \\
\hline \multirow{2}{*}{ Guideline } & Yes & 78 & 86 & $1.39(0.93,2.06)$ & $1.43(0.89,2.27)$ \\
\hline & No & 101 & 155 & 1 & 1 \\
\hline \multirow{2}{*}{ Budget } & Yes & 32 & 35 & $1.28(0.75,2.16)$ & $1.08(0.58,2.00)$ \\
\hline & No & 147 & 206 & 1 & 1 \\
\hline \multirow{2}{*}{ Rewarding } & Yes & 59 & 74 & $1.11(0.73,1.68)$ & $1.12(0.73,1.81)$ \\
\hline & No & 120 & 167 & 1 & 1 \\
\hline \multirow{2}{*}{ Training } & Yes & 111 & 66 & $1.66(1.12,2.45)$ & $1.71(1.08,2.71)^{*}$ \\
\hline & No & 122 & 121 & 1 & 1 \\
\hline
\end{tabular}




\begin{tabular}{|c|c|c|c|c|c|}
\hline $\begin{array}{c}\text { Availability of } \\
\text { sufficient }\end{array}$ & Yes & 101 & 84 & $1.81(0.83,1.81)$ & $1.20(0.72,1.99)$ \\
\hline Color coded bin & No & 140 & 95 & 1 \\
\hline \multirow{2}{*}{ Availability of PPE } & Yes & 113 & 74 & $1.25(0.85,1.85)$ & $1.10(0.66,1.84)$ \\
\cline { 2 - 6 } & No & 128 & 81 & 1 \\
\hline $\begin{array}{c}\text { Personal needs to use } \\
\text { PPE }\end{array}$ & Yes & 169 & 98 & 1 & 1 \\
\cline { 2 - 6 } & No & 72 & 60 & $1.51(1.01,2.25)$ & $1.15(1.97,4.45)^{*}$ \\
\hline \multirow{2}{*}{ Knowledge } & Adequate & 104 & 119 & 1 & 1 \\
\cline { 2 - 6 }
\end{tabular}

Key * = Represents variables significantly associated at P-value is $\leq 0.05, \mathrm{AOR}=$ Adjusted Odds Ratio, COD = Crude Odds Ratio, $\mathrm{PPE}$ $=$ Personal Protective Equipment, OPD= Outpatient Diagnosis.

\section{Discussion}

This study aimed to assess the knowledge, practice and associated factors towards health care waste segregation among health care providers at University of Gondar Comprehensive Specialized Hospital. The overall prevalence of knowledge of HCPs was $39 \%$ and practice was $42.6 \%$. In the present study Knowledge of HCPs on health care waste segregation were $39 \%$ which was lower than studies done in South Africa 47.2\% [18], India 50\% [17]. The possible reasons to this difference may be organizational structure, resource utilization and possibility of HCWM training. However, the current finding is higher than studies done in Egypt 32. 4\% [16]. This could be due the reason that the degree of emphasis of health care facilities on healthcare waste management, on job training and the accessibility of healthcare waste management documents in the working environment.

Practice of HCPs on health care waste segregation were 42.6\% which is lower than studies done in Bangladesh 56\% [9], Cairo 84.8\% [13], Haramaya $47 \%$ [23]. The possible explanation for this variation might be due to accessibility of equipment, working environment and health care setting. Regarding factors, respondents who received training were 1.81 times more likely to have adequate knowledge on HCWS compared to respondents who had not received HCWM training. Which is supported by a study conducts in India [17]. It might be individuals who received training used to gain several information and simultaneously participants become knowledgeable regarding HCWS. Participants who were rewarded were 1.8 times more likely to have adequate knowledge towards HCWS as compared to those participants who were not. It is because participants who were rewarded by their managers have increased affinity towards their work which leads them to read and explore knowledge that can increase their awareness towards HCWS.

Respondents who received training were 1.71 times more likely to have appropriate practice on HCWS compared to respondents who did not receive HCWM training. This is in line with a study conducted in India and Gondar, participants who received training was achieved appropriate health care waste segregation practice $[5,24]$. This similarity might be due to individuals who received training may gain appropriate information and help them to know the way of waste placing in different waste bin to achieve appropriate practice of health care waste segregation. The respondents who use PPE for HCW handling had 3.15 times more likely apply appropriate practice compared to who do not use PPE for HCW handling which is similar with a study conducted in Bangladesh, participants who used PPE for handling of health care waste were achieved appropriate health care waste segregation practice [27]. And the other similarity might be the nature of health care waste is noxious and the participants who were not interested to use PPE were disposing inappropriately in to the nearest bin but a participant who uses PPE to be handling HCW had better practice.

\section{Limitation of the Study}

The study design was cross sectional, which measures the exposure and outcome simultaneously but cannot measure the cause and effect relationship.

\section{Conclusion}

This study showed that health care provider's knowledge and practice towards health care waste segregation in University of Gondar Comprehensive Specialized hospital was inadequate. Training and reward were factors for knowledge and also training and personal needs to use personal protective equipment for handling health care waste segregation were factors for practice of health care providers on health care waste segregation.

\section{Acknowledgement}

We would like to forward our deepest gratitude to the University of Gondar for financial support. Also, we are highly indebted to acknowledge the study participants who participated in this research.

\section{References}

1. Chartier Y (2014) Safe management of wastes from health-care activities. World Health Organization.

2. Haifete AN (2016) Knowledge, attitude and practice of health care workers on waste segregation at two public training hospitals, in Khomas region, Namibia. University of Namibia.

3. WHO, United Nations' Children's Fund (2015) Water, sanitation and hygiene in health care facilities: Status in low and middle income countries and way forward. Water sanitation hygiene p. 35.

4. Mansab MR (2014) Sharp waste management at kidongo chekundu national mental hospital zanzibar tanzania. Master's thesis, The Open University of Tanzania. 
5. Kumar M, Singh RK, Umesh VR (2015) Awareness and practices about bio-medical waste among Health care workers in Tertiary care hospital of Haldwani, Semantic Scholar 159: 72-73.

6. Ola-Adisa EO, Mangden EY, Sati YC, Adisa JO (2015) Knowledge, attitudes, beliefs and practices in medical waste management-an appraisal of Jos north Lga, Plateau State, Nigeria. Int J Res Humanities and Social Studies 2(12): 43-56.

7. Muduli K, Barve A (2012) Challenges to waste management practices in Indian health care sector. International Conference on Environment Science and Engieering, IACSIT Press, Singapoore. Volume 32.

8. Ismail IM, Kulkarni AG, Kamble SV, Borker SA, Rekha R, et al. (2013) Knowledge, attitude and practice about bio-medical waste management among personnel of a tertiary health care institute in Dakshina Kannada, Karnataka. Al Ameen J Med Sci 6(4): 376-380.

9. Sarker MA, Harun-Or-Rashid M, Hirosawa T, Abdul Hai MS, Siddique MR, et al. Evaluation of knowledge, practices, and possible barriers among healthcare providers regarding medical waste management in Dhaka, Bangladesh. Med Sci Monit 20: 2590-2597.

10. Sanjeev R, Kuruvilla S, Subramaniam R, Prashant P, Gopalakrishnan M (2014) Knowledge, attitude, and practices about biomedical waste management among dental healthcare personnel in dental colleges in Kothamangalam: A cross-sectional study. Health Sciences 1(3): 1-12.

11. Kumar R, Samrongthong R, Shaikh BT (2013) Knowledge, attitude and practices of health staff regarding infectious waste handling of tertiary care health facilities at metropolitan city of Pakistan. J Ayub Med Coll Abbottabad 25(1-2): 109-112.

12. Mostafa GM, Shazly MM, Sherief WI (2009) Development of a waste management protocol based on assessment of knowledge and practice of healthcare personnel in surgical departments. Waste Manag 29(1): 430-439.

13. Hakim SA, Mohsen A, Bakr I (2014) Knowledge, attitudes and practices of health-care personnel towards waste disposal management at Ain Shams University Hospitals, Cairo. East Mediterr Health J 20(5): 347354.

14. Haifete AN, Justus AH, Iita H (2016) Knowledge, attitude and practice of healthcare workers on waste segregation at two public training hospitals. Euro J Pharmaceu Med Res 3(5): 674-689.

15. Makhura RR (2016) Knowledge and practices of health care workers on medical waste disposal in Mapulaneng Hospital in the Ehlanzeni District of South Africa. University of Limpopo.

ISSN: 2574-1241

DOI: $10.26717 / B J S T R .2018 .09 .001847$

Tarkie Abebe. Biomed J Sci \& Tech Res

This work is licensed under Creative

Commons Attribution 4.0 License

Submission Link: https://biomedres.us/submit-manuscript.php
16. Nour MO, Babilghith AO, Natto HA, Al-Amin FO, Alawneh SM (2015) Knowledge, attitude and practices of healthcare providers towards MERS-CoV infection at Makkah hospitals, KSA. Int Res J Med Med Sci 3(4): 103-112.

17. Gupta NK, Shukla M, Tyagi S (2017) Knowledge, attitude and practices of biomedical waste management among health care personnel in selected primary health care centres in Lucknow. Int J Community Med Public Health. 2016; 3(1): 309-313.

18. Makhura RR, Matlala SF, Kekana MP (2016) Medical waste disposal at a hospital in Mpumalanga Province, South Africa: Implications for training of healthcare professionals. S Afr Med J 106(11): 1096-1102.

19. Mesfin A, Worku W, Gizaw Z (2014) Assessment of health care waste segregation practice and associated factors of health care workers in Gondar university hospital, North West Ethiopia, 2013. Universal J Public Health 2(7): 201-207.

20. Manga VE, Forton OT, Mofor LA, Woodard R (2011) Health care waste management in Cameroon: A case study from the Southwestern Region. Resources, Conservation and Recycling 57: 108-116.

21. Azuike EC, Adinma ED, Nwabueze SA, Azuike ED, Mbanuzuru VA, et al (2015) Healthcare waste management: What do the health workers in a Nigerian tertiary hospital know and practice. Science 3(1): 114-118.

22. Alemayehu T, Alemayehu W, Assefa N (2015) Community risk perception on healthcare wastes in hospitals and health centres of Eastern Ethiopia. Sciences Journal of Public Health 3(1): 37-43.

23. Azage M (2013) Healthcare waste management practices among healthcare workers in healthcare facilities of Gondar town, Northwest Ethiopia. Health Science Journal 7(3): 315-326.

24. Ananth AP, Prashanthini V, Visvanathan C (2010) Healthcare waste management in Asia. Waste Manag 30(1): 154-161.

25. Olukanni DO, Azuh Dominic E, Toogun Tunde O, Okorie Uchechukwu Emenas, (2014) Medical waste management practices among selected health-care facilities in Nigeria: A case study. Academic Journals 9(10): 431-439.

26. Biswas A, Amanullah AM, Santra SC (2011) Medical waste management in the tertiary hospitals of Bangladesh: An empirical enquiry. ASA Univ Rev 5(2): 10.

27. Molina VB (2002) Waste management practices of Hospitals in Metro Manila. University of the Philippines Manila Journal 7(3-4): 17-22.

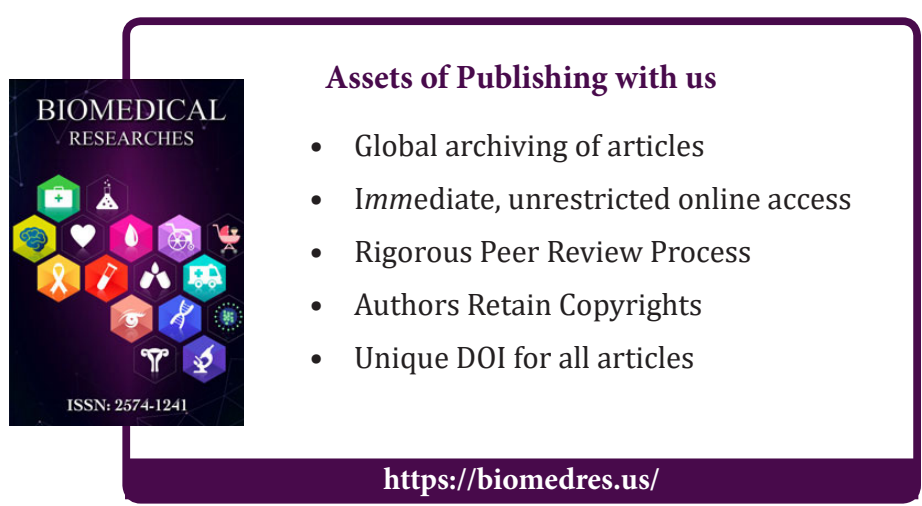

Cite this article: AbebaFenta Tewabe, Bewket Tadesse T,YaredAsmare A, TarkieAbebe W. Knowledge, Practice and Barriers of Health Care Wastes Segregation Among Health Care Providers in University of Gondar Comprehensive Specialized Hospital, Northwest Ethiopia, 2017.

Biomed J Sci\&Tech Res 9(4)-2018. BJSTR. MS.ID.001847. DOI:10.26717/ BJSTR.2018.09.001847. 